\title{
Internal Flow Optimization in a Complex Profile Extrusion Die Using Flow Restrictors and Flow Separators
}

\author{
Jingyang Xing \\ Lehigh University \\ Majed Alsarheed \\ Lehigh University \\ Animesh Kundu ( $\sim$ ank8@lehigh.edu ) \\ Lehigh University \\ John P. Coulter \\ Lehigh University
}

\section{Research Article}

Keywords: Profile extrusion, Die design, Flow optimization, Post-Die extrudate deformation

Posted Date: July 6th, 2021

DOI: https://doi.org/10.21203/rs.3.rs-660555/v1

License: (c) (i) This work is licensed under a Creative Commons Attribution 4.0 International License. Read Full License

Version of Record: A version of this preprint was published at The International Journal of Advanced Manufacturing Technology on January 13th, 2022. See the published version at https://doi.org/10.1007/s00170-021-08306-6. 


\title{
Internal Flow Optimization in a Complex Profile Extrusion Die Using Flow Restrictors and Flow Separators
}

\author{
Jingyang Xing ${ }^{1}$, Majed Alsarheed ${ }^{2}$, Animesh Kundu ${ }^{1}$, and John P. Coulter ${ }^{1}$ \\ ${ }^{1}$ Manufacturing Science Laboratory, Lehigh University, 19 Memorial Drive West, Bethlehem, PA, 18015, USA \\ ${ }^{2}$ Noortek LLC, 4883 Skytop Drive, Emmaus, PA, 18049, USA \\ Corresponding author: John P. Coulter, john.coulter@lehigh.edu
}

\section{Acknowledgments}

The authors would like to acknowledge the financial support from the State of Pennsylvania through the PA

Manufacturing Fellows Initiative (PMFI) and the Manufacturing PA Innovation Program. The guidance and support provided by Coleen Mantini and Jennifer Leinbach who oversee the program is greatly appreciated. 


\begin{abstract}
The control of flow balance at the die exit is the key for successful extrusion of polymers. The complex crosssectional variation in real-world hollow extrusion profiles intrinsically promotes flow imbalance in the die cavity. Special considerations are required for designing extrusion dies for such profiles. The die design for a complex door frame profile was computationally optimized in this study with the aid of a commercially available software package. The velocity distribution at the die exit, post-die extrudate deformation, temperature distribution, and pressure distribution of a traditional die was investigated in detail and found to be inadequate. A modified die incorporated three distinct features, flow restrictors, flow separators and approach angle of the torpedoes, to achieve a balanced and uniform velocity at the die exit. The flow restrictors and flow separators were added in the preparallel zone. Flow restrictors were added on top and bottom of the torpedoes to increase the restriction on polymer flow. A unique inclined flow restrictor was introduced to achieve uniform internal melt flow. Flow separators were added at junctions of outer wall and inner vertical walls to separate the polymer flow into different sections and minimize cross flow between these sections. The addition of these features proved to be highly effective for balancing the velocity distribution at the die exit. The combination of 3-D modeling and simulation is an effective cost and time efficient approach for optimizing complex die designs before manufacturing.
\end{abstract}

Keywords: Profile extrusion, Die design, Flow optimization, Post-Die extrudate deformation 


\section{Introduction}

Extrusion is the most utilized process for high volume manufacturing of constant cross-section plastic products, such as pipes, tubes, and sheets [1]. Complex hollow profiles are also produced via a "profile extrusion" technique for diverse applications in the construction industry. Door and window frames are presumably the best example of complex hollow profiles. Such profiles have intricate cross-sections with large variations in wall thicknesses, intrinsically promoting an unbalanced polymer melt flow inside the extrusion die. The complexity of profile extrusion processes requires critical attention and expertise to the die design process for balanced internal flow. The extrusion dies for complex profiles are often designed empirically and the processing conditions are adjusted during the operation to obtain an acceptable product, which is neither efficient nor optimal. With the advent of computer aided engineering (CAE) approaches and availability of powerful computers and software packages, it is now possible to evaluate different designs in a virtual environment and develop extrusion dies with balanced flow. This has made the entire die design process more efficient and economical [2]. However, the process still requires an experienced user with a thorough understanding of the polymer melt rheology and the flow behavior of the melt in the cavity die.

One important consideration for designing an extrusion die is to have a uniform velocity distribution across the entire cross-section of the profile at the die exit. Post-die extrudates are typically in semi-solid form and can deform readily if the extrusion die is not balanced properly. The internal polymer flow is relatively easier to balance for simple profiles such as slits, conduits, and rods. For complex profiles, the die geometry and the final shape of the extrudate are difficult to determine because of the swell phenomena that occurs during polymer extrusion [3]. The different thicknesses of the walls impose varying degrees of flow restrictions and naturally result in an unbalanced melt flow in the die cavity. The flow of polymer in the thicker section is less restricted as compared to that in the thinner section. This results in a higher flow velocity in thicker sections, a lower flow velocity in thinner sections and the melt from a higher velocity tends to flow toward the melt with a lower velocity. This flow redistribution can cause profile deformation after the die exit. Hence it is imperative to understand the velocity distribution inside 
the complex profile extrusion dies as well as predict post-die extrudate deformation for efficient and cost-effective production in an industrial setting.

A conventional extrusion die has four sections (zones): adapter, transition zone, pre-parallel (pre-land) zone, and parallel (land) zone [4]. Polymer coming out of the extruder goes into the adapter that connects the extrusion die to the extruder and transitions from primarily rotational to longitudinal motion. The material then flows through each subsequent zone until it reaches the die exit. In the transition zone, polymer flow changes from circular shape to complex shape by either expanding or compressing, depending on shape and size of the profile. In the pre-parallel zone, the melt flow is redirected in a controlled fashion to the parallel zone, where the polymer is extruded to its final shape and held to ensure adequate dimensional stability.

Typically, there are two methods for balancing the flow through an extrusion die [5]. The first approach involves adjusting land lengths of the pre-parallel and parallel zones, and adding flow restrictors to control the high velocity polymer flow. For a complex profile die this implies a change in the length and approaching angle of torpedoes to attain an identical polymer flow at the die exit. The approaching angle of torpedoes can be changed by adjusting the shape of the torpedoes in the area where the torpedoes are expanding.

The second approach involves the incorporation of flow separators inside the extrusion die to separate the melt flow into different sections in a controlled fashion. Flow separators are incorporated in the pre-parallel zone to form different flow channels for the polymer melt. These flow channels can control the polymer flow volume and guide the polymer melt to the parallel zone. The primary objective to minimize melt crossflow is often referred to as an 'avoid cross-flow' strategy [6]. This method is often used in complex profile extrusion dies since cross flow occurs more frequently in between the sections in such dies. Flow separators are added on top of the gap between each torpedo to separate polymer flow into vertical and horizontal sections.

In this research, a computer aided design approach was utilized to design an extrusion die for a complex hollow profile with uniform flow velocity at the die exit. The design strategy involved incorporation of both flow restrictors and separators at strategic locations in the die. A novel flow restrictor design was proposed and its efficacy on the melt flow uniformity at the die exit was evaluated by numerical simulations. The non-isothermal polymer melt flow inside the extrusion die assembly was numerically simulated with the aid of a software package. The influence of 
strategically placed flow separators and restrictors on the internal melt flow and the associated effects on the melt temperature, pressure and shear stresses were studied in detail. Post-die extrudate deformation was also analyzed and was related to polymer velocity distribution.

\section{Extrusion Die Design Strategy}

A complex hollow extrusion profile utilized in an actual production facility for the fabrication of wood polymer composite (WPC) door frames was selected. The cross-sectional view of the profile is presented in Fig.1. The overall width of the profile is $200 \mathrm{~mm}$ and the overall height in $37 \mathrm{~mm}$ with a uniform outer wall thickness of 2.6 $\mathrm{mm}$. The vertical inner walls have a thickness of $2.0 \mathrm{~mm}$. The bottom left and right sections are thicker with serrated features, the thickness of these sections is $3 \mathrm{~mm}$. A plastic part gets inserted into the gap between the serrated overhang and the main body during installation of such a door frame, and the serrated features provide additional friction and a tighter fit during this process. The small square opening on the right top corner hold a soft rubber bumper in application. These profile features provide significant challenges in designing an extrusion die that would provide a uniform velocity distribution at the die exit.

A die similar in design to the actual die utilized in the production line was initially considered for this study. The detailed die design is presented in Fig. 2. The total die length was $264 \mathrm{~mm}$ between die inlet and exit, with a preparallel zone length of $75 \mathrm{~mm}$ and a parallel zone length of $85 \mathrm{~mm}$. In the transition zone, polymer flow was changed from circular shape to the complex shape of the extrudate. In the pre-parallel zone, the melt flow was redirected in a controlled fashion to the parallel zone, where the polymer was extruded to its final shape. A series of torpedoes in the pre-parallel and parallel zone (Fig. 2b) was added to ensure that the final shape was formed accurately. The die was designed without any consideration of the melt flow behavior in the die assembly. No flow separators or restrictors were incorporated in this initial design.

Although the die was utilized in the industry for wood plastic composite (WPC) door frames, poly-vinyl chloride (PVC) was considered in the numerical simulations to investigate the melt flow behavior in this study. The WPC relevant for door frames typically consists of wood flour or powder mixed with PVC and wide range of additives with specific functionalities such as heat stabilizers [7], impact modifiers [8], lubricants, and processing aids [9]. 
Actual WPC formulations can be diverse and are often proprietary. As such the rheological properties are seldom studied and publicly reported on in detail. Hence, a generic rigid polyvinyl chloride (PVC) was considered for the numerical simulations. It was assumed that actual WPC formulations utilized in industry would have similar trends in rheological properties as the PVC.

The melt flow behavior in the initial die (Fig. 2) was modelled with the aid of Altair Inspire Extrusion Polymer software. The spatial distribution of the velocity of the melt at the die exit was critically assessed. An innovative approach was adopted to minimize crossflow and velocity imbalance at the die exit. Both flow restrictors and flow separators were incorporated in the pre-parallel zone. Traditionally, either flow restrictors or flow separators are incorporated in the die. Additionally, the geometry of the flow restrictors was changed from the traditional rectangular cross-section to triangular shapes to fine tune the flow behavior. The approach angle of the torpedoes was changed as well to attain optimal flow behavior at the die exit.

\section{Modelling of Polymer Melt Flow}

\subsection{Material and Rheology Properties}

A generic rigid PVC was considered for numerical simulations. The physical properties of the PVC are presented in Table 1. A cross-WLF model was utilized to model the rheological properties of the PVC. In this model the viscosity $(\eta)$ is determined as follows [10]:

$$
\eta=\frac{\eta_{0}}{1+\left(\frac{\eta_{0} \dot{y}}{\tau^{*}}\right)^{1-n}}
$$

Where $\eta$ is the melt viscosity $(\mathrm{Pa} \cdot \mathrm{s}), \eta_{0}$ is the zero-shear viscosity or the 'Newtonian limit' in which the viscosity approaches a constant at very low shear rates, $\dot{\gamma}$ is the shear rate $(1 / \mathrm{s}), \tau^{*}$ is the critical stress level at the transition to shear thinning or reference shear stress, and $\mathrm{n}$ is the power law index in the high shear rate regime.

The zero-shear viscosity $\eta_{0}$ is calculated by the following equation [11]:

$$
\eta_{0}=D_{1} \exp \left[-\frac{A_{1}\left(T-T^{*}\right)}{A_{2}+\left(T-T^{*}\right)}\right] \quad 3-2
$$


Where $T^{*}=D_{2}+D_{3} p$ and $A_{2}=\tilde{A}_{2}+D_{3} p$ and $D_{1}, D_{2}, D_{3}, A_{1}, \tilde{A}_{2}$, are experimentally derived empirical coefficients. $p$ is the pressure on the polymer melt.

The Cross-WLF model is a 6 parameter model that describes both shear thinning and Newtonian behaviors [12]. It is the most common model that considers the effects of shear rate, temperature and pressure on the viscosity and offers a best fit for most viscosity data [13]. The WLF model (equation 3-2) for temperature dependence is generally applicable for amorphous polymers at moderate temperatures [12]. It is appropriate for this work as PVC could be considered as an amorphous polymer. An alternative model for temperature dependence, the Arrhenius model, primarily applies to semi-crystalline polymers and amorphous polymers at high temperatures $\left(T>T_{g}+100 \mathrm{~K}\right)$ [12].

The appropriate rheological constants for the PVC as obtained from Altair Inspire Extrusion Polymer software database is provided in Table 1. The relevant physical properties for the PVC are shown in Table 2.

\subsection{Simulation Conditions}

The simulation conditions were chosen to be representative of real manufacturing conditions for PVC window profiles and have been adopted from the literature. The inlet velocity at the beginning of the transition zone was set to be $12.5 \mathrm{~mm} / \mathrm{s}$. The adapter area for the die was $2358 \mathrm{~mm}^{2}$, resulting in a volumetric flow rate of $0.10611 \mathrm{~m}^{3} / \mathrm{h}$. The resultant mass flow rate was calculated to be $88.37 \mathrm{~kg} / \mathrm{h}$, assuming the density of PVC to be $832 \mathrm{~kg} / \mathrm{m}^{3}$. The inlet melt temperature and wall temperature were set at $428 \mathrm{~K}\left(155^{\circ} \mathrm{C}\right)$ and $443 \mathrm{~K}\left(170^{\circ} \mathrm{C}\right)$ respectively. The postdie extrudate was simulated for $100 \mathrm{~mm}$ in a stress-free condition. This condition is applied to all boundaries of the extrudate. In order to simulate a real convection condition, the cooling temperature of the extrudate was set to be $303 \mathrm{~K}\left(30^{\circ} \mathrm{C}\right)$, and a convection heat transfer coefficient of $1 \mathrm{~W} / \mathrm{m}^{2} \mathrm{~K}$ was utilized. These parameters were kept identical for all the numerical simulations. In the simulations, a no-slip condition was assumed at the die wall. The polymer melt was considered to be an incompressible fluid [14]. 


\subsection{Mesh Generation}

The 3D model of the polymer melt in the die was spatially discretized using the Altair HyperMesh ${ }^{\mathrm{TM}}$ finite element pre-processor. A combination of hexahedral and tetrahedral elements was utilized to conform to the complex geometry accurately and obtain results with adequate detail. Hexahedral elements were applied on the parallel zone and post-die extrudate since there was no geometry change at these sections [15]. Tetrahedral elements were applied on the transition zone and the pre-parallel zone to adequately represent the complex geometry changes at these sections. The total number of nodes and elements were 906,891 and 2,258,636, respectively. The meshed model is shown in Fig. 3(a). The part was divided into different sections for the simulation software. The different sections of the polymer melt are presented in different shades of gray in the figure. The lightest gray is the melt in the transition zone, the lighter gray is the melt in the pre-parallel zone, the darker gray is the melt in the parallel zone, and the darkest gray is the post-die extrudate. An expanded two-dimensional view of the connection of preparallel and parallel zone is presented in Figure 3(b). The tetrahedral elements in the pre-parallel zone are at the top while the hexahedral elements are shown in the parallel zone in the bottom section in the figure.

\section{Results and Discussion}

\subsection{Initial Extrusion Die Results}

The flow velocity distribution at the die exit of the conventional die is shown in Fig. 4. Because of the different thicknesses in the different sections of the profile, the polymer melt experienced varying degrees of restriction. This resulted in an imbalanced flow distribution at the die exit. The velocity varied by more than 2 times from section to section at the die exit. The average velocity in the outer section with a thickness of $2.6 \mathrm{~mm}$ was $25.9 \mathrm{~mm} / \mathrm{s}$. The average velocity in the inner sections with $2.0 \mathrm{~mm}$ thickness was $13.0 \mathrm{~mm} / \mathrm{s}$. In the serrated sections at the bottom left and right the average velocity was even higher $(33.0 \mathrm{~mm} / \mathrm{s})$, as shown in Fig. 4 . The thickness of these sections was $3 \mathrm{~mm}$. The highest velocity $(45 \mathrm{~mm} / \mathrm{s})$ was observed at the bottom left and right sections at the intersection of the thick horizontal serrated sections and the thin vertical inner sections (Figure 4b). The melt velocity was generally 
higher at the center of most of the junctions between the horizontal sections and inner vertical sections. The flow was less restrictive at these regions because they were further away from the die walls, hence the increased velocity.

The simulated post-die extrudate deformation in $x, y$, and $z$ axes at a distance of $100 \mathrm{~mm}$ out of the die is shown in Fig. 5. The $x$ axis is horizontal, and the $y$ axis is vertical on the plane of the paper. The $z$ axis is vertical to the plane of the paper parallel to the extrusion direction. The deformation was primarily confined to the outer peripheries. The horizontal deformation ( $x$ axis) was minimal. The maximum deformation $(1.3 \mathrm{~mm})$ was at the right side. The deformation in the $y$ axis direction was somewhat symmetric. A maximum deformation of $\sim 9 \mathrm{~mm}$ was observed at the serrated sections at both bottom left and right. The maximum deformation along $z$ axis was also at the serrated sections at bottom left and right, the magnitude was $\sim 13.5 \mathrm{~mm}$. The effect of the distortions on the three orthogonal directions will act collectively on the extrudate. The simulated extrudate cross-section at $100 \mathrm{~mm}$ out of the die is presented in Fig. 6 in solid color overlaid on the outline of the intended cross-section. The outer left and right sections deformed upwards while the middle part deformed in the opposite direction. The overall distortion was maximum at the bottom section $(15.8 \mathrm{~mm})$, coinciding with the region with maximum velocity at the die exit. The results indicate that the conventional die would produce a deformed extrudate which would most likely be unacceptable in practice.

Pressure distribution in the melt in the die cavity was simulated, the results are shown in Fig. 7a. The pressure at the die exit was set to be at atmospheric pressure (0.1 MPa, zero-gauge pressure). The highest pressure (20.17 MPa) was observed at the beginning of transition zone. The pressure decreased continuously from the transition zone to the die exit. At these pressures PVC is not expected to degrade in any fashion. The temperature distribution in the melt in the die cavity is shown in Fig. 7b. PVC, being a thermally sensitive material, is prone to degradation at high temperatures $>250^{\circ} \mathrm{C}[16]$. The die inlet temperature was set at $428 \mathrm{~K}\left(155^{\circ} \mathrm{C}\right)$ and the extrusion die wall temperature at $443 \mathrm{~K}\left(170^{\circ} \mathrm{C}\right)$. The temperature stayed within this range for the most part. The temperature in certain regions in the polymer melt exceeded the die wall temperature to a maximum of $\sim 180^{\circ} \mathrm{C}$. It was believed to be caused by shear heating of the melt at the die wall. 


\subsection{Modifications of Extrusion Die and Effects on Flow Balancing}

An optimal extrusion die should have a uniform flow distribution at the die exit, ensuring minimal post-die extrudate deformation. Traditionally, the length of the parallel zone is increased to reduce the flow imbalance. In this research the length of the parallel zone was kept constant. A series of innovative modifications were incorporated in the initial die to achieve a more uniform flow distribution at the die exit.

1. Flow restrictors were added on the top and bottom of each torpedo in the pre-parallel zone for added restriction to polymer melt flow in these sections as shown in Fig. 8 for one of the representative torpedoes. The flow restrictors, highlighted with a crosshatch pattern in the figure, were set to be $1.6 \mathrm{~mm}$ in height, $31.5 \mathrm{~mm}$ in width, and $75 \mathrm{~mm}$ in length. In addition, a pair of inclined restrictors were added in the preparallel zone to further reduce the velocity in the serrated sections. The velocity was highest in these sections in the initial die. A cross-sectional view of the modified extrusion die with the inclined restrictors is shown in Fig. 9. The inclined restrictor had a triangular cross section, the maximum height was set to be $2 \mathrm{~mm}$ at the junction of the vertical section and the serrated section and gradually reduce to a sharp end at the edge of the serrated section. The width of the inclined restrictor was $27.5 \mathrm{~mm}$ and the length was $75 \mathrm{~mm}$. A minor flow restrictor on the vertical wall of the torpedo of the right section was also incorporated in the modified die. This minor flow restrictor was set to be $0.9 \mathrm{~mm}$ in height, $21 \mathrm{~mm}$ in width, and $75 \mathrm{~mm}$ in length.

2. A set of flow separators was added between each torpedo at the top and the bottom of the die to minimize the cross flow between the outer section and inner vertical section as shown in Fig. 10. The isometric view of the left side of the pre-parallel zone from the back of the die is shown in the figure, the separators are marked with black and white stripes and highlighted with white circle. Each separator was $3.15 \mathrm{~mm}$ in height, $2 \mathrm{~mm}$ in width and $85 \mathrm{~mm}$ in height.

3. In addition, the gap between the torpedoes was increased from $2 \mathrm{~mm}$ to $4 \mathrm{~mm}$ in the parallel zone to reduce the flow restriction. In the modified die the polymer flow was thus compressed later than the original conventional die. These modifications are highlighted in Figure 11. Additional space between torpedoes was provided in the pre-parallel zone as well, to enhance the flow velocity. 
The final dimensions and positions of the aforementioned features in the modified die was achieved in an iterative fashion. The flow velocity at the die exit was simulated for a specific combination of flow restrictors and flow separators and their number, position and dimensions were adjusted systematically to realize an optimal design.

The velocity distribution at the die exit of the final modified die is presented in Figure 12. The average velocity of the extrudate increased modestly from $23 \mathrm{~mm} / \mathrm{s}$ in the original die to $26 \mathrm{~mm} / \mathrm{s}$ in the modified die. However, the velocity distribution improved drastically in the modified die. The average flow velocity was $28.0 \mathrm{~mm} / \mathrm{s}$ in the outer $2.6 \mathrm{~mm}$ sections in the modified die as compared to $25.9 \mathrm{~mm} / \mathrm{s}$ in the same section in the original die. The average velocity in the inner $2.0 \mathrm{~mm}$ sections increased to $23.0 \mathrm{~mm} / \mathrm{s}$ in the modified die from $13 \mathrm{~mm} / \mathrm{s}$ in the original die. The flow velocity at the serrated sections reduced to $25.0 \mathrm{~mm} / \mathrm{s}$ in the modified die from $33 \mathrm{~mm} / \mathrm{s}$ in the original die. Furthermore, the modified die successfully eliminated the high velocity "hot spots" at the junctions between the vertical and horizontal sections observed in the original die (Fig. 12b)

With a more balanced velocity distribution, the magnitude of post-die extrudate deformation was also reduced. The deformation of the extrudate at $100 \mathrm{~mm}$ from the die exit along the three orthogonal directions for the modified die is presented in Fig. 13. The deformation along $x$ axis (Fig. 13a) was minimal in the original die $(1.3 \mathrm{~mm}$ maximum). It was further reduced to $0.97 \mathrm{~mm}$ with the modified die. The deformation along $y$ axis was nominal for most part (Fig. 13b) with the modified die. A significant improvement was observed on the right side of the extrudate. The deformation of the serrated section on the right side was $\sim 3 \mathrm{~mm}$ (as compared to $\sim 9 \mathrm{~mm}$ with the original die). The serrated section on the left side had a maximum deformation of $7.8 \mathrm{~mm}$. Minor adjustment of the restrictors in this section could further minimize the deformation. The deformation along the $z$ axis experienced the most improvement (Fig 13c). The maximum deformation along the $z$ axis was reduced to $6.4 \mathrm{~mm}$ with the modified die from $13.5 \mathrm{~mm}$ with the original die. The simulated extrudate cross-section at $100 \mathrm{~mm}$ out of the die, shown in Fig. 14, reflected the efficacy of the modified die as well. The deformation was minimal for most part, only minor deformation was observed in the top left section and serrated section in the bottom right. In an extrusion production line, the extrudate will pass through a calibrator unit usually located very close to the die exit. The primary function of the calibrator is to shape the semi-solid extrudate to it final dimensions as it cools to room temperature [17]. In this research, the deformation of the extrudate was measured at $100 \mathrm{~mm}$ from die exit to amplify the distortions. At 
the calibrator location, the deformation will be lower than the values presented earlier. It is expected that the calibrator will be able to rectify the deformation observed at the bottom-left and top-right corners of the extrudate with the modified die.

The temperature and pressure distribution in the polymer melt in the modified die were also determined. It was observed that the addition of the flow restrictors and the flow separators did not change the pressure distribution drastically. The pressure decreased continuously from the transition zone to the die exit in a similar fashion as with the initial die. The maximum pressure was observed at the beginning of the transition zone ( 26 MPa). The maximum temperature in the melt in the modified die was $\sim 180^{\circ} \mathrm{C}$, identical to the melt in the original die. However, the maximum temperature was observed more frequently in the melt in the modified die. PVC is not expected to degrade in any fashion under these conditions.

\section{Conclusion}

An innovative die design approach was introduced for balancing the melt flow in a complex hollow extrusion profile die for a door frame. The Altair Inspire Extrude Polymer software package was utilized to assess the flow velocity at die exit, the associated extrudate deformation and the temperature and pressure distributions in the polymer melt in the die cavity. The flow characteristics of a standard prototype die were initially determined to be highly nonuniform. A series of die features were incorporated to develop a modified die. The features included flow restrictors and flow separators in the pre-parallel zone. A unique inclined flow restrictor was found to be critical for balancing the melt flow at the peripheral overhanging sections. The inclined flow restrictor had a triangular cross-section in contrast to traditional restrictors that have a rectangular cross-section. The gaps between the torpedoes were also adjusted. The velocity differential at the die exit was reduced from $40 \mathrm{~mm} / \mathrm{s}$ in the initial extrusion die to $\sim 5 \mathrm{~mm} / \mathrm{s}$ with the modified die. The maximum deformation of the extrudate at $100 \mathrm{~mm}$ from the die exit was reduced from $11 \mathrm{~mm}$ with the initial die to $4 \mathrm{~mm}$ with the modified die. The incorporation of the flow separators and flow restrictors did not affect the temperature and pressure distributions detrimentally in the die cavity. It is anticipated 
that this work would provide realistic guidance for the design of complex hollow profile extrusion dies to the practitioners in the field. 


\section{Declarations}

\section{Funding}

Financial support for this project was provided by the State of Pennsylvania through the PA Manufacturing

Fellows Initiative (PMFI) and the Manufacturing PA Innovation Program

\section{Conflicts of interest/Competing interests.}

The authors declare that they have no competing interests.

\section{Availability of Data and Material}

The related data is available from the corresponding author John Coulter upon a reasonable request. 


\section{References}

1. Gonçalves ND, Teixeira P, Ferrás LL, Afonso AM, Nóbrega JM, Carneiro OS (2015) Design and optimization of an extrusion die for the production of wood-plastic composite profiles. Polym Eng Sci 55:1849-1855. https://doi.org/10.1002/pen.24024

2. Narayanasamy R, Srinivasan P, Venkatesan R (2003) Computer aided design and manufacture of streamlined extrusion dies. J Mater Process Technol 138:262-264. https://doi.org/10.1016/S0924$\underline{0136(03) 00082-7}$

3. Hurez P, Tanguy PA, Blouin D (1996) A new design procedure for profile extrusion dies. Polym Eng Sci 36:626-635. https://doi.org/10.1002/pen.10450

4. Lee WS, Ho HY (2000) Experimental study on extrudate swell and die geometry of profile extrusion. Polym Eng Sci 40:1085-1094. https://doi.org/10.1002/pen.11236

5. Shahreza AR, Behravesh AH, Jooybari MB, Soury E (2010) Design, optimization, and manufacturing of a multiple-thickness profile extrusion die with a cross flow. Polym Eng Sci 50:2417-2424. https://doi.org/10.1002/pen.21770

6. A. S. E. Pradeep ASE (2016) Design features and optimization of profile extrusion dies. Master's Thesis, Michigan Technological University

7. Doworkin RD (1989) PVC Stabilizers of the past, present, and future. J Vinyl Technol 11:15-22. https://doi.org/10.1002/vnl.730110106

8. Mengeloglu F, Matuana LM, King JA (2000) Effects of impact modifiers on the properties of rigid PVC/wood-fiber composites. J Vinyl Addit Technol 6:153-157. https://doi.org/10.1002/vnl.10244

9. Kokta BV, Maldas D, Daneault C, Béland P (1990) Composites of poly (vinyl chloride) and wood fibers. Part II: Effect of chemical treatment. Polym Compos 11:84-89. https://doi.org/10.1002/pc.750110203

10. Cross MM (1965) Rheology of non-Newtonian fluids: A new flow equation for pseudoplastic systems. J Colloid Sci 20:417-437. https://doi.org/10.1016/0095-8522(65)90022-X

11. M. L. Williams ML, R. F. Landel RF, and J. D. Ferry JD (1955) The temperature dependence of relaxation mechanisms in amorphous polymers and other glass-forming liquids. J Am Chem Soc 77:3701-3707. https://doi.org/10.1021/ja01619a008

12. Lenk RS (2012) Polymer rheology. Springer Science \& Business Media

13. Hieber CA, Chiang HH (1992) Shear-rate-dependence modeling of polymer melt viscosity. Polym Eng Sci 32:931-938. https://doi.org/10.1002/pen.760321404

14. Summers JW, Rabinovitch EB, Quisenberry JG (1985) A scientific approach to rigid poly(vinyl chloride) extrusion. J Vinyl Technol 7:32-35, 1985. https://doi.org/10.1002/vnl.730070108

15. Cifuentes AO, Kalbag A (1992) A performance study of tetrahedral and hexahedral elements in 3-D finite element structural analysis. Finite Elem Anal Des 12:313-318. https://doi.org/10.1016/0168$\underline{874 X(92) 90040-\mathrm{J}}$ 
16. Yu J, Sun L, Ma C, Qiao Y, Yao H (2016) Thermal degradation of PVC: A review. Waste Manag 48:300-314. https://doi.org/10.1016/j.wasman.2015.11.041

17. Nóbrega JM, Carneiro OS, Covas JA, Pinho FT, Oliveira PJ (2004) Design of calibrators for extruded profiles. Part I: Modeling the thermal interchanges. Polym Eng Sci 44:2216-

2228. https://doi.org/10.1002/pen.20249 


\section{Figure Captions}

\begin{tabular}{|c|c|}
\hline Fig. 1: & $\begin{array}{l}\text { A cross-sectional view of the complex hollow door frame profile considered in this study. All } \\
\text { dimensions are in millimeters }\end{array}$ \\
\hline Fig. 2: & $\begin{array}{l}\text { (a) An engineering drawing of the extrusion die geometry, and (b) a cutaway isometric view of the } \\
\text { die showing the torpedoes inside the extrusion die. The dimensions are in millimeters. }\end{array}$ \\
\hline Fig. 3: & $\begin{array}{l}\text { (a) Isometric view of the overall mesh of the polymer melt in the extrusion die. The different } \\
\text { sections are shown in different colors. The lightest gray is the melt in the transition zone, the lighter } \\
\text { gray is the melt in the pre-parallel zone, the darker gray is the melt in the parallel zone, and the } \\
\text { darkest gray is the post-die extrudate. The tetrahedral elements in pre-parallel zone is at the top } \\
\text { while the hexahedral elements are shown in the parallel zone in the bottom section in the figure. }\end{array}$ \\
\hline Fig. 4: & $\begin{array}{l}\text { (a) Cross-sectional view of the polymer velocity distribution at the die exit of the initial extrusion } \\
\text { die, and (b) detail view of the right side on the melt showing the maximum velocity region. }\end{array}$ \\
\hline Fig. 5: & $\begin{array}{l}\text { Cross-sectional view of post-die extrudate deformation at } 100 \mathrm{~mm} \text { from the die exit for the initial } \\
\text { die in three orthogonal directions; (a) } x \text { axis, parallel to the horizontal axis of the paper (b) } y \text { axis, } \\
\text { parallel to the vertical axis, and (c) } z \text { axis, normal to the plane of the paper. }\end{array}$ \\
\hline Fig. 6: & $\begin{array}{l}\text { Overall deformation of the post-die extrudate at } 100 \mathrm{~mm} \text { from the die exit for the initial die. The } \\
\text { original shape is shown by the solid outline. }\end{array}$ \\
\hline Fig. 7: & $\begin{array}{l}\text { (a)Isometric view of the pressure distribution of the polymer melt of the initial extrusion die, and (b) } \\
\text { isometric view of the temperature distribution of the polymer melt of the initial extrusion die. }\end{array}$ \\
\hline Fig. 8: & $\begin{array}{l}\text { An isometric view of a representative torpedo highlighting the flow restrictors with a crosshatch } \\
\text { pattern. All the torpedoes had identical flow restrictors at the top and bottom. }\end{array}$ \\
\hline Fig 9: & $\begin{array}{l}\text { A cross-sectional view of the inclined flow restrictor on the right side of the profile showing the } \\
\text { exact location and shape of the inclined flow restrictor. The inclined flow restrictor is highlighted } \\
\text { with a crosshatch pattern }\end{array}$ \\
\hline
\end{tabular}




\begin{tabular}{|l|l|}
\hline Fig. 10: & $\begin{array}{l}\text { An isometric view of the left side of the pre-parallel zone from the back of the die showing the } \\
\text { position of the flow separators. The flow separator is circled and highlighted with a crosshatch } \\
\text { pattern. }\end{array}$ \\
\hline Fig. 11: & $\begin{array}{l}\text { A cross-sectional view of the torpedoes. The torpedoes in the initial die is shown in dark gray and those in the } \\
\text { modified die is shown in light gray. The modified region is marked with a black rectangle. }\end{array}$ \\
\hline Fig. 12: & $\begin{array}{l}\text { (a) Cross-sectional view of the polymer velocity distribution at the die exit of the modified extrusion } \\
\text { die, and (b) detail view of the right side of the melt. }\end{array}$ \\
\hline Fig. 13: & $\begin{array}{l}\text { Cross-sectional view of post-die extrudate deformation at } 100 \text { mm from the die exit for the modified } \\
\text { die in three orthogonal directions; (a) } x \text { axis, parallel to the horizontal axis of the paper (b) } y \text { axis, } \\
\text { parallel to the vertical axis, and (c) } z \text { axis, normal to the plane of the paper. }\end{array}$ \\
\hline Fig. 14: & $\begin{array}{l}\text { Overall deformation of the post-die extrudate at } 100 \text { mm from the die exit for the modified die. The } \\
\text { original shape is shown by the solid outline. }\end{array}$ \\
\hline
\end{tabular}




\section{Table Captions}

\begin{tabular}{l|l}
\hline Table 1: & Relevant viscosity model parameters for PVC utilized for simulations.
\end{tabular}

Table 2: $\quad$ Relevant properties of PVC utilized for simulations. 


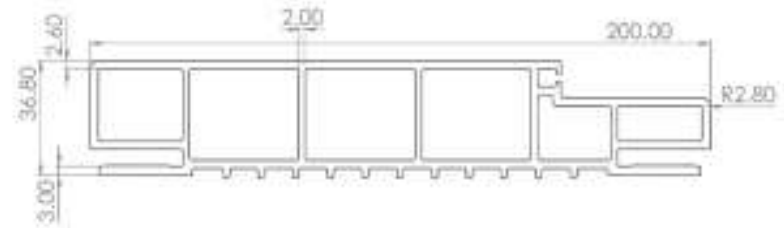

Fig. 1. 

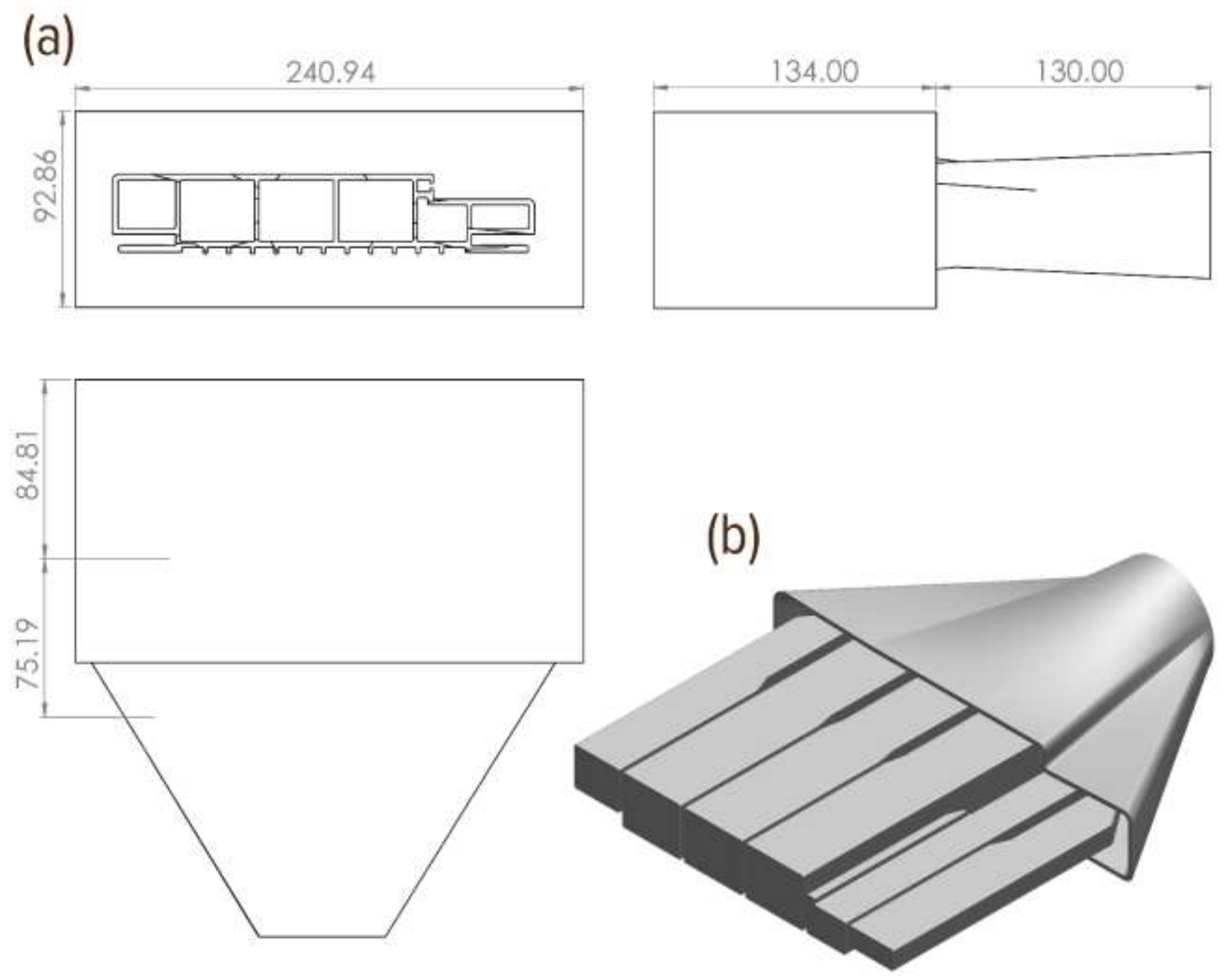

Fig. 2 


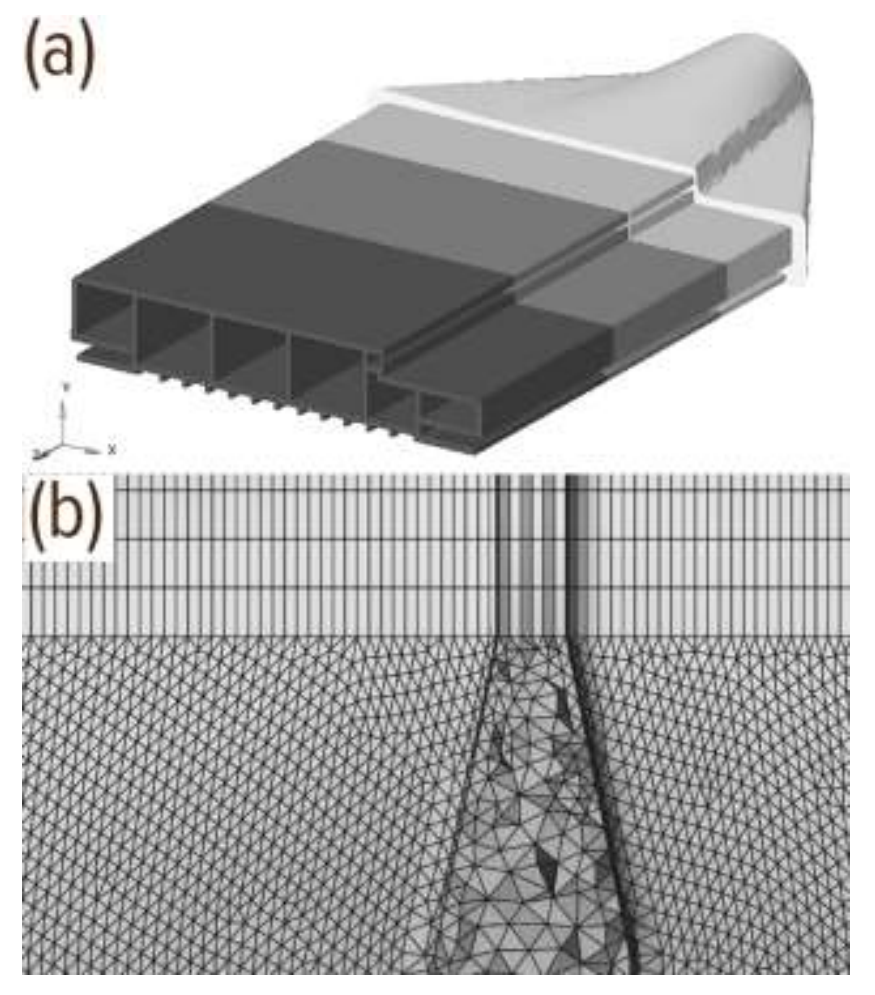

Fig. 3 
(a)
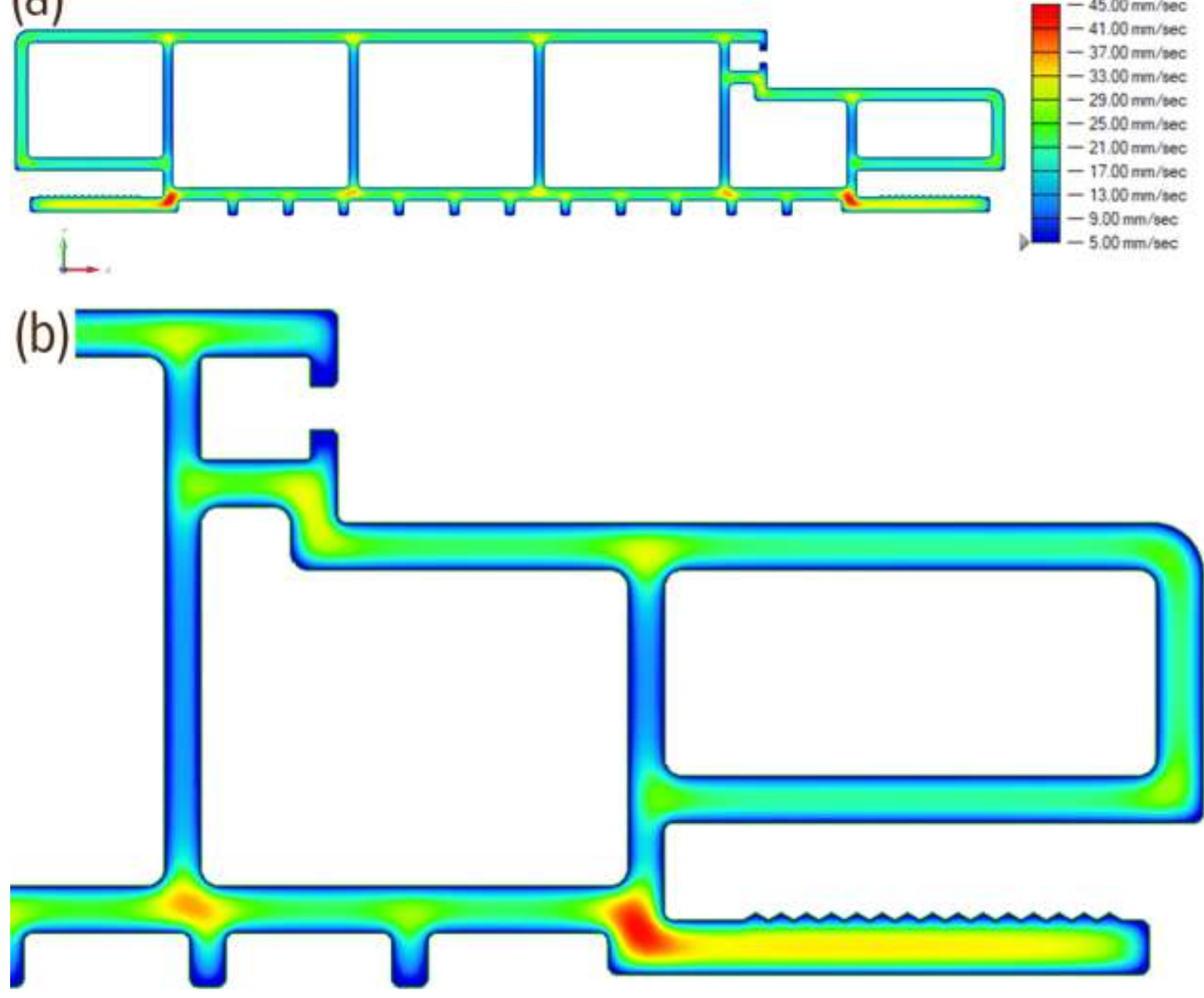

Fig. 4 
(a)

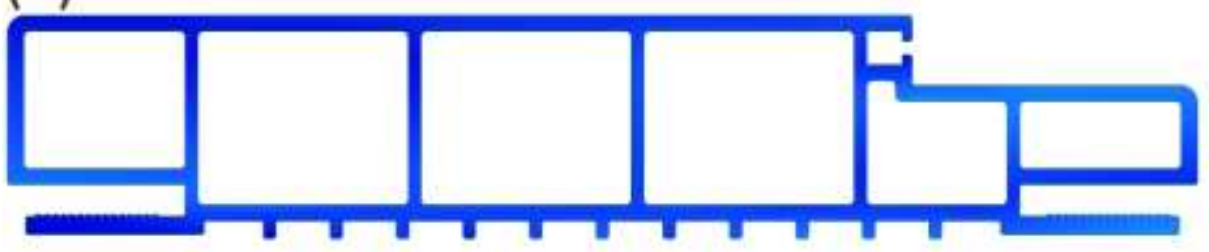

(b)

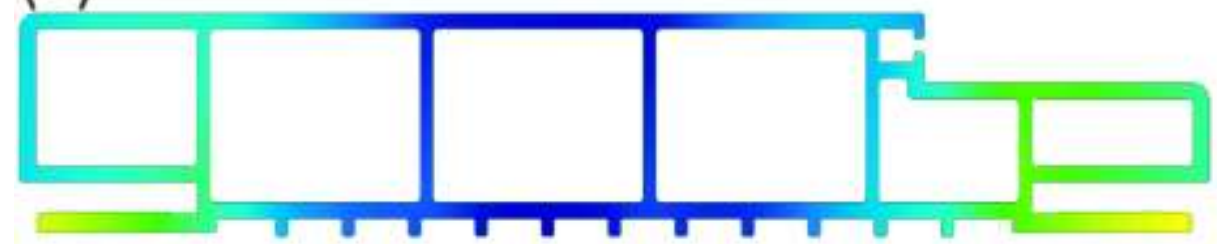

(c)
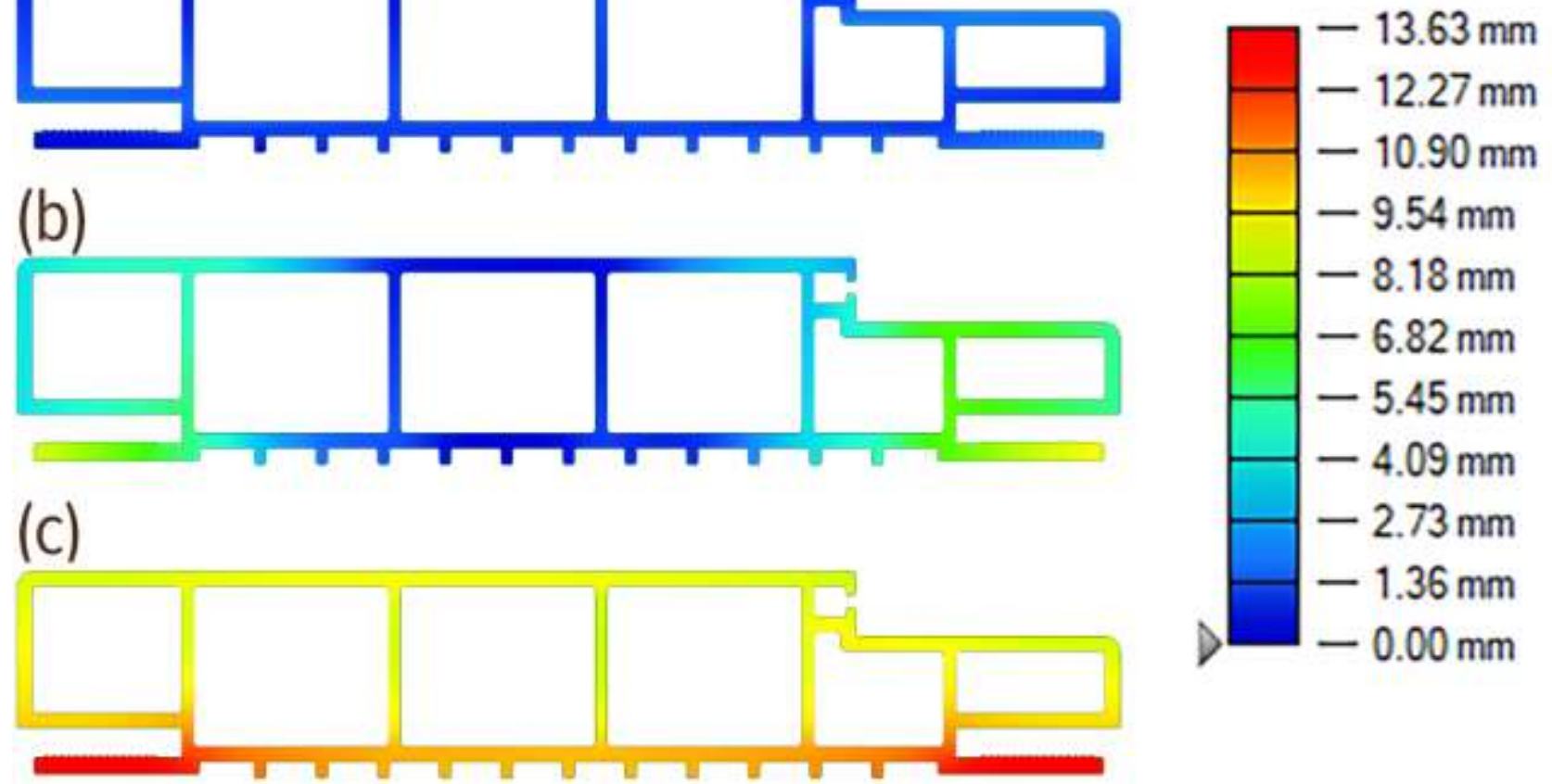

Fig. 5 


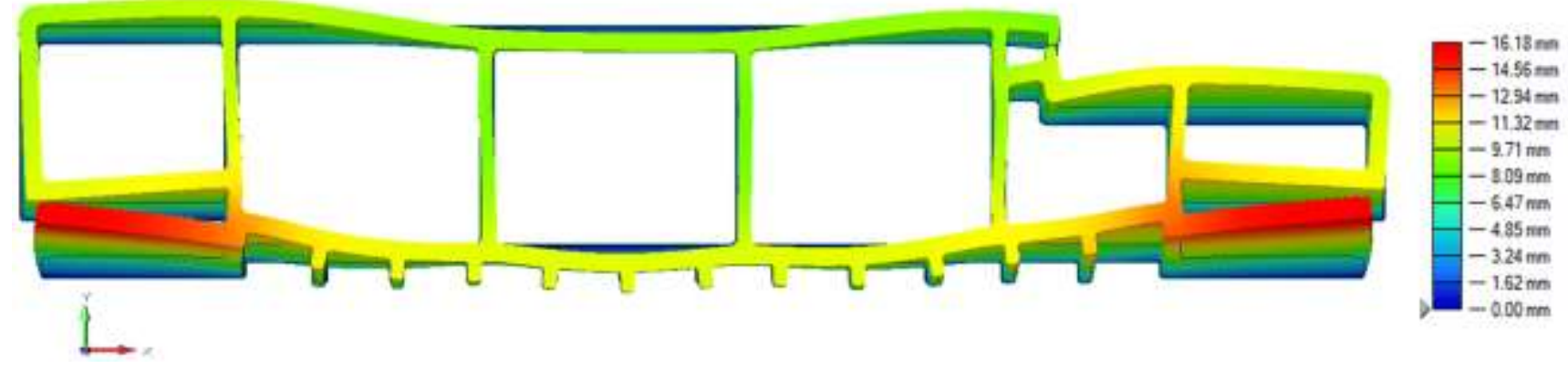

Fig. 6 

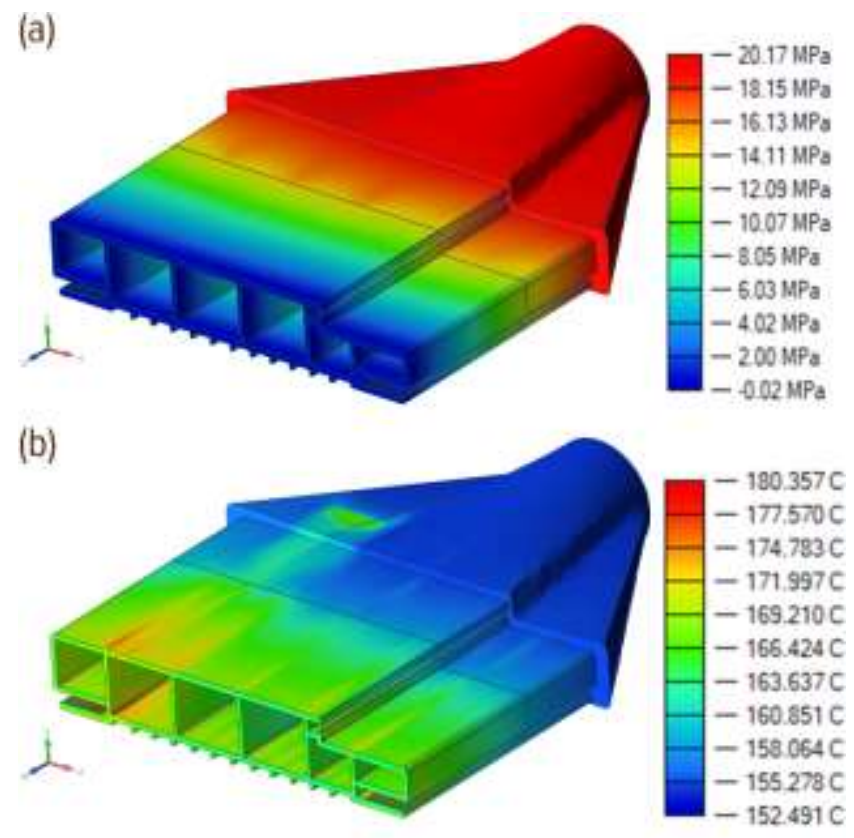

Fig. 7 


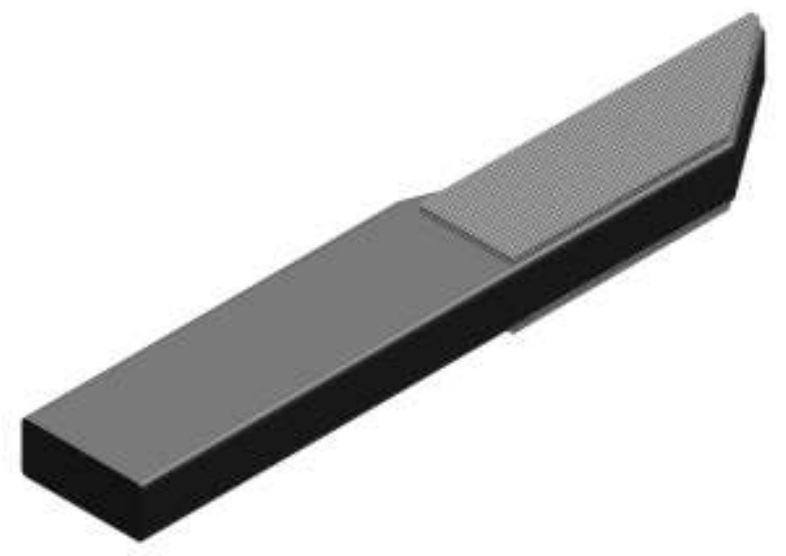

Fig. 8 


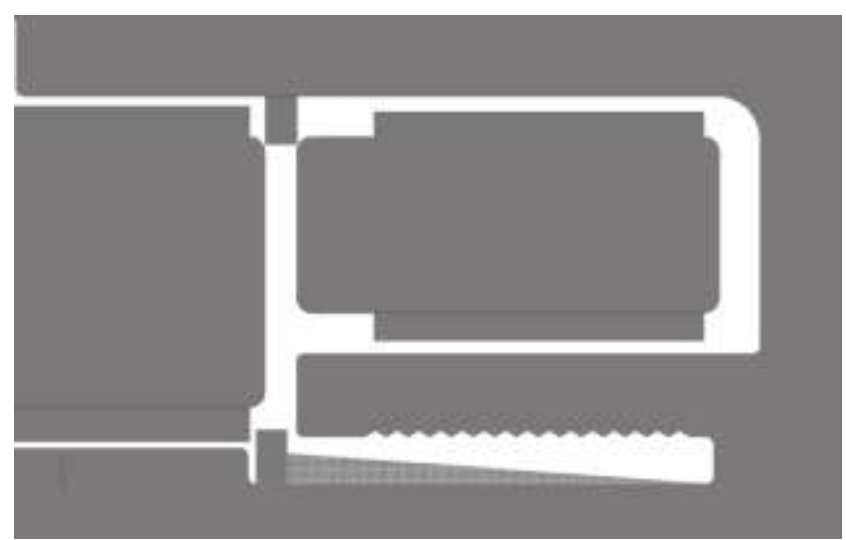

Fig. 9 


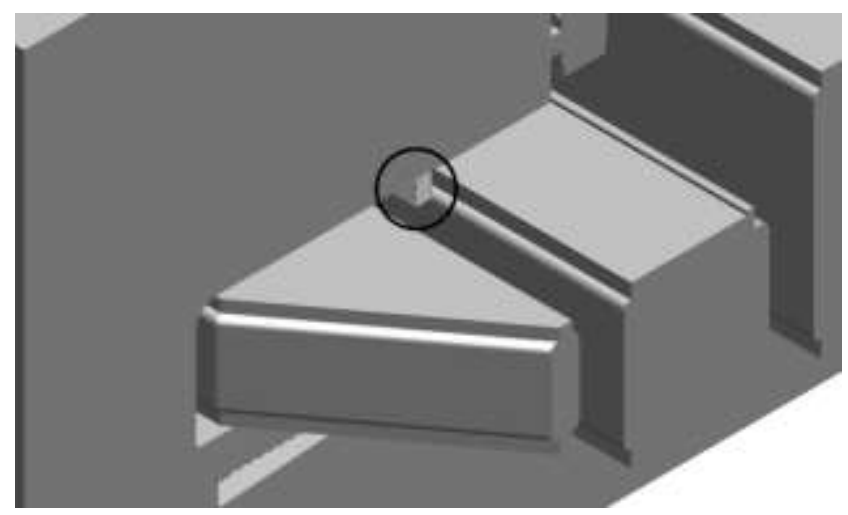

Fig. 10 


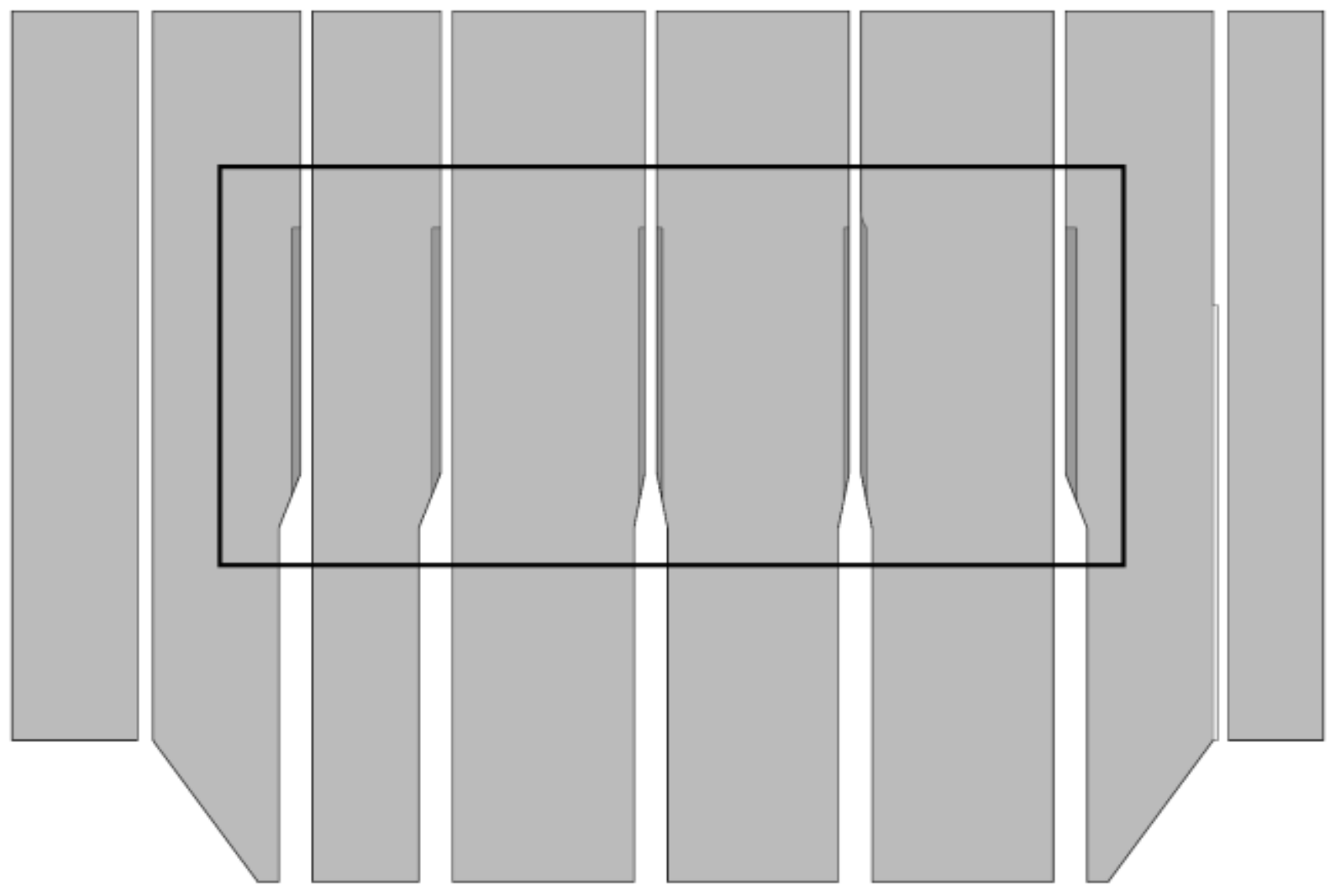

Fig. 11 
(a)
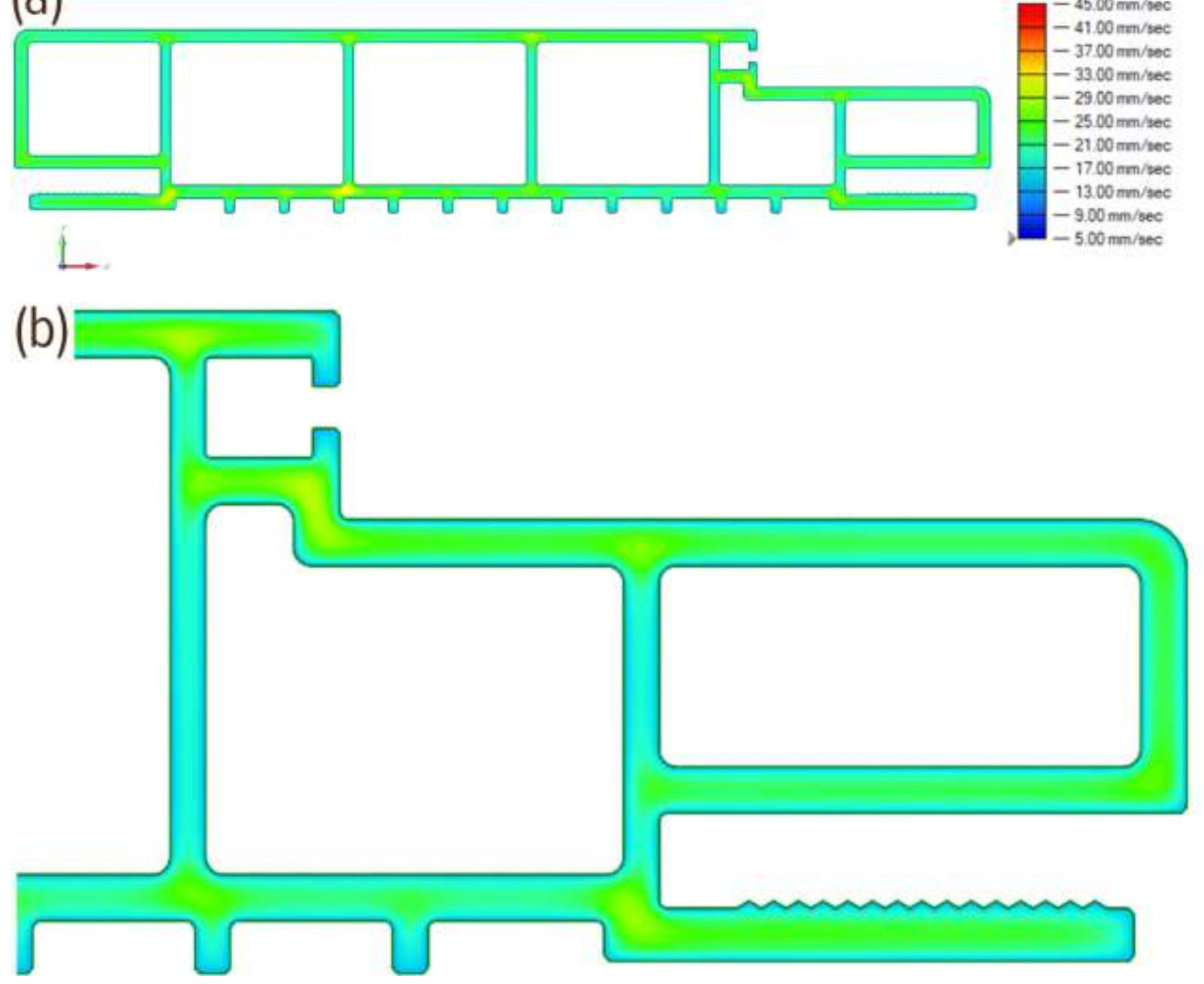

Fig. 12 
(a)

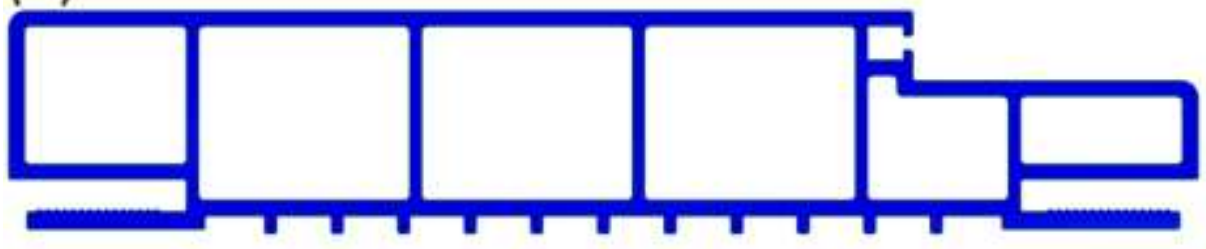

(b)

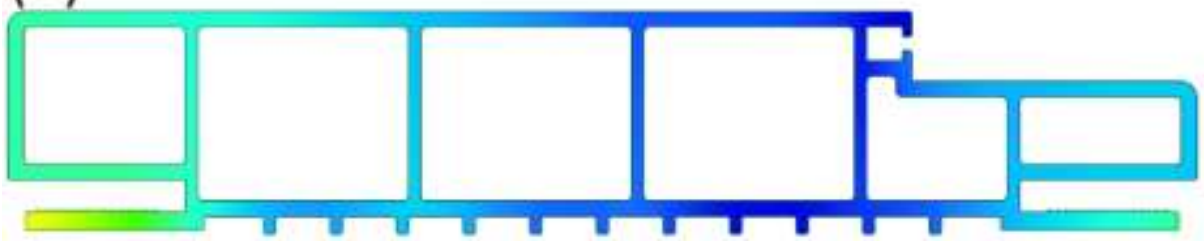

(c)
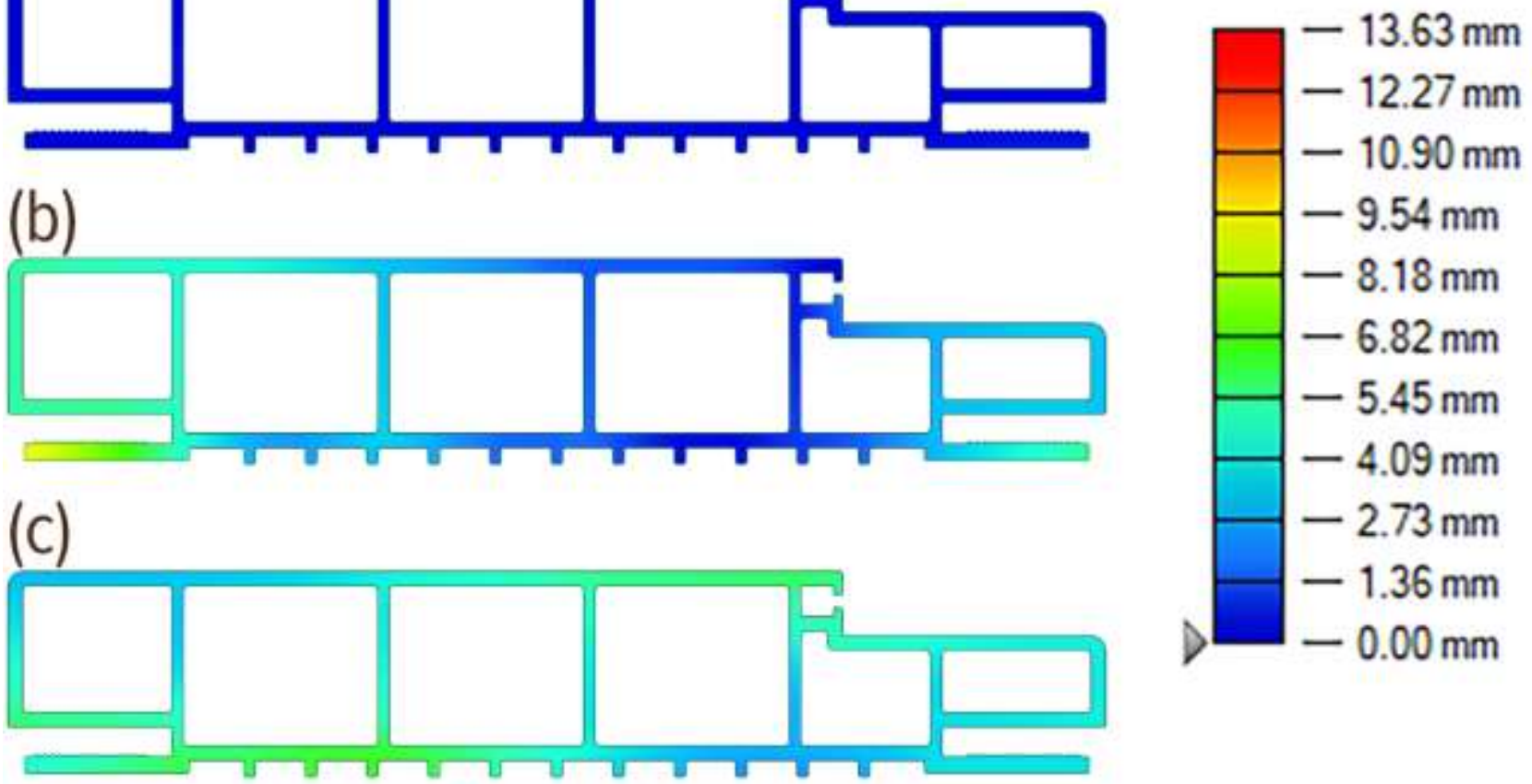

Fig. 13 


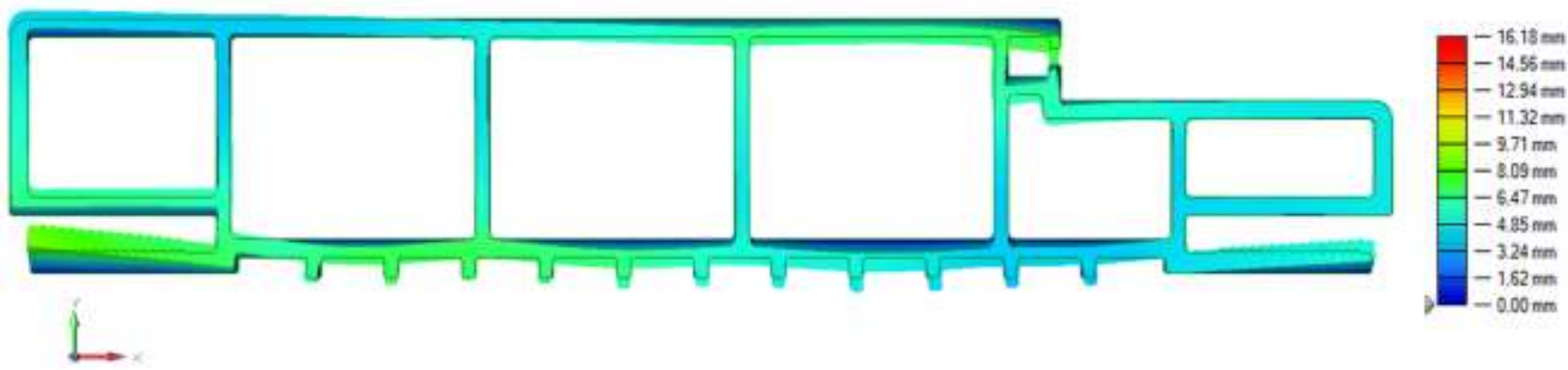

Fig. 14 
Table 1

\begin{tabular}{|c|c|}
\hline Viscosity Model Parameters & \\
\hline $\mathrm{D} 1(\mathrm{~Pa}-\mathrm{s})$ & $8.41841 \mathrm{e}+18$ \\
\hline $\mathrm{A} 1$ & 33.7371 \\
\hline $\mathrm{A} 2(\mathrm{~K})$ & 51.6 \\
\hline $\mathrm{T}^{*}(\mathrm{~K})$ & 353 \\
\hline$\tau^{*}(\mathrm{~Pa})$ & 5100.37 \\
\hline $\mathrm{n}$ & 0.274187 \\
\hline
\end{tabular}


Table 2

\begin{tabular}{|c|c|}
\hline Properties (units) & \\
\hline Density $\left(\mathrm{kg} / \mathrm{m}^{3}\right)$ & 832.779 \\
\hline Specific Heat $(\mathrm{J} / \mathrm{kg}-\mathrm{K})$ & 2642.15 \\
\hline Conductivity $(\mathrm{W} / \mathrm{m}-\mathrm{K})$ & 0.1978 \\
\hline Thermal Expansion $(1 / \mathrm{K})$ & $1 \mathrm{e}-05$ \\
\hline
\end{tabular}

